\title{
Analyzing the Influencing Factors of Group Learning: A Mixed Approach
}

\author{
Jianhua Zhao \\ School of Information Technology in Education, South China Normal University, Guangzhou, 510631, China \\ Email: jhuazhao@gmail.com \\ Yinjian Jiang \\ School of Foreign Languages, Guangdong Polytechnic Normal University, Guangzhou, 510665, China \\ Email: georgina29@126.com
}

\begin{abstract}
The purpose of this paper is to explore which factors influence group learning content, and content analysis is chosen as the research method. The sample for this study is the literature of group learning. 35 books and 1 paper was examined. The coding system for the content analysis is an opened and a self-expanded system in this study, which means that the original coding system can be updated if the new coding item is developed during the data collection. A total of 62 influencing factors are identified in terms of the content analysis. In order to organise them systematically, we categorised them into four aggregations according to one model of the group learning processes: planning, organising, learning process, and evaluation. The result of this study may be used to design a questionnaire and to model group learning process in our further research.
\end{abstract}

Index Terms-group learning, influencing factors, coding system, content analysis

\section{INTRODUCTION}

Much research has already been carried out into group learning, such as group problem solving [1][2], computer-supported group learning [3][4], cooperative learning group [5][6][7], and virtual group learning [8]. When one reviews the work of the field, one can easily find that there has only been a few studies which address the factors that influence group learning [9][10]. To know which factors will influence group learning, it is important for the field of e-learning research, especially for this study, which will focus on how to use computer to facilitate group learning.

The factors influencing the performance and effectiveness of a group learning process were defined as the influencing factors of group learning in this study, such as group task, group composition, group communication, group interaction, group structure, and group evaluation. McGrath proposes a paradigm to analyze group interaction (see Figure 1) [11].

McGrath devises a framework in this paradigm, i.e.

Manuscript received January 8, 2009; revised June 9, 2009; accepted July 10, 2009.
"INPUT $\rightarrow$ PROCESS $\rightarrow$ OUTPUT" for analyzing the roles of the group interaction process. The INPUT component includes individual-level factors, group-level factors, and environment-level factors. The OUTPUT component includes performance outcomes and other outcomes [11]. This paradigm manifests the different influencing factors of group learning. However, it does not clarify how many influencing factors are involved in the different components. Hackman and Morris develop a framework to explain the relationship among the focal input variables, the group interaction process, the summary variables, the critical task contingencies, and group performance and effectiveness (see Figure 2) [12]. Three categories of variables are involved in this paradigm, i.e. effort, performance strategies, and knowledge and skill. Hackman and Morris consider these three categories of variables are the most proximal causes of group task effectiveness. Similar with McGrath's paradigm, this framework can be described as an "Input-Process-Output" sequence for different types of tasks [11].

These variables can be considered as the influencing factors of group learning process in this study, i.e. group composition, group norms, group task, group performance, and group interaction. However, they do not explicate how many influencing factors are involved in this process. Other researchers, such as Jaques and Reynolds, also mention the influencing factors of a group learning process [9][10]. However, they do not introduce the influencing factors of them systematically.

In this study, we are going to explore which factors influence group learning processes. In order to identify these factors, we compare some related field works [13][14][15] and choose content analysis as our research method. Content analysis is a research technique for making replicable and valid inferences from data to their context [14]. Conventionally, content analysis can be considered as a qualitative method. But Berg argues that "content analysis can be considered as a blend of qualitative and quantitative method" [15]. We prefer this perspective. In this study, we will use a qualitative method to identify the factors first, and then use quantitative methods to extract which factors are more essentially related to group learning processes. By this 
we suggest that these factors will influence group learning process more.

INPUT

INDIVIDUAL-LEVEL
FACTORS
(i.e., pattern of member skills,
attitudes, personality,
characteristics)

GROUP-LEVEL FACTORS
(i.e., structure, level of
“cohesiveness", group size)

ENVIRONMENT-LEVEL
FACTORS
(i.e., group task characteristics,
reward structure, level of
environmental stress

TIME

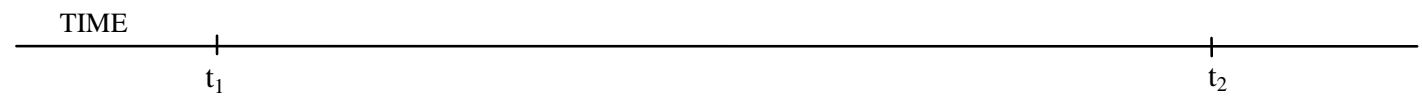

Figure 1. A traditional paradigm for analysis of group interaction as a mediator of performance outcomes

Figure 2. An input-process-output sequence framework for different types of tasks

It is important to know explicitly the relevant influencing factors of a group learning process in order to analyze and utilize them in-depth. These factors are related to the different stages of group learning process, such as group organizing, group process, and group performance. If the influencing factors of a group learning process were identified, they could be used to devise and manage this process intentionally. If a tutor was familiar with these influencing factors, it could help her/him to organize a group learning process effectively for her/is teaching.

Two approaches could be employed to find out the influencing factors of group learning process. The first approach was to analyze the actual group learning processes and to extract the relevant influencing factors via a series of experiments. However, it was a timeconsuming approach and difficult to ensure these influencing factors could be extracted completely. The second approach was to analyze them from relevant literature. The relevant research had already been undertaken in the field. To analyze the literature would help us to effectively find out these influencing factors.

\section{MethodOLOGY}




\section{A. Content Analysis}

Content analysis is a research technique for making replicable and valid inferences from data to their context [16]. Its purpose is to provide knowledge, new insights, a representation of "facts", and a practical guide to action. McKernan states that content analysis focuses on the inquiring into the deeper meaning and structure of a message or communication [17]. The messages may be contained in a written document, a communications broadcast, film, video, or in actual human behavior observed. The purposes are to explore the hidden themes, concepts, and indicators of the message contents. Therefore, content analysis can be considered as a tool that can be used to explore the specific data. Researchers will examine artifacts of social communication in content analysis, such as documents, transcriptions, and videotapes.

Normally, the data of content analysis is qualitative, rather than quantitative. Therefore, it is a qualitative method. The qualitative aspect of content analysis includes examining ideological mind-sets, themes, topics, symbols, and similar phenomena. However, Berg argues that content analysis can be considered as a blend of qualitative and quantitative method [18]. A series of tally sheets to determine specific frequencies of relevant categories will link with its quantitative aspect. This study views content analysis as a blended method, which is quite similar to Berg's viewpoint.

The purpose of content analysis in this study could be summarized as: to analyze the relevant literature and to find out the influencing factors of a group learning process. These factors could be used to design the specific questionnaires to examine the differences of group learning in the classroom-based and the web-based settings.

The data for content analysis in this study includes two categories, i.e. quantitative and qualitative data. The qualitative data was collected from the relevant literature, i.e. books, and journal papers about group learning. These materials provided the systematic and synthetically perspectives on analyzing group learning process.
A coding system was developed in order to use content analysis first. The primary coding system was developed according to analysis of McGrath's model and Hackman and Morris's model [11][12]. This coding system was an open system, which means that the new influencing factors of a group learning process could be identified and added to this coding system during the content analysis process.

Data analysis provided the frequency and percentage of the influencing factors in the literature, which were the quantitative data of content analysis. The influencing factors were extracted according to the significance of their frequency and percentage.

\section{B. Sampling}

The research about group learning in the literature presented its social, psychological, political, and educational characteristics, which formed a group learning research community in the field. The outcomes and achievements of this community could be considered as the population of this study, such as books, papers (journals and conferences), reports, or theses. The relevant issues of this study included group performance, group interaction, group conflict, group leadership, group role, group communication, group dynamic, group structure, group process, and group work. These issues represented the population of this study.

Group research in literature is already related to its various aspects, such as social, psychological, political, educational characteristics. The samples in this study are chosen from typical books and journal papers in the group learning research field. The issues include group performance, group interaction, group conflict, group leadership, group communication, group dynamic, group structure, group role, group process, and group work, which represent the essential of group. The influencing factors of group learning can be extracted from these issues by content analysis. The name of each sample can be defined according to their original book title. For this purpose, we define a set of names for the samples which are described in Table I.

TABLE I.

THE NAME OF THE SAMPLES

\begin{tabular}{rccc}
\hline No & $\begin{array}{c}\text { The Name of } \\
\text { Samples }\end{array}$ & The Title of the Literature & $\begin{array}{c}\text { The type of } \\
\text { Samples }\end{array}$ \\
\hline 1 & CL & Communication and Learning in Small Group & B \\
2 & LG & Learning in Groups & B \\
3 & WG & Working in Groups: Communication Principles and Strategies & B \\
4 & SG & Small Group Learning in the Classroom & B \\
5 & GP & Group Process: Papers from Advances in Experimental Social Psychology & B \\
6 & GT & Group Theory for Social Works: An Introduction & B \\
7 & GA & Groups at Work & B \\
8 & GR & Groupwork & B \\
9 & GK & Groupwork Practice & B \\
10 & DG & Dynamics of Group Action & B \\
11 & MG & Learning from Others in Groups: Experimental Learning Approaches & B \\
12 & GE & Group Dynamics \& Individual Development & B \\
13 & GD & Interaction in Cooperative Groups: The Theoretical Anatomy of Group Learning & B \\
14 & IC & Group Tutoring, Concepts and Case Studies & B \\
15 & GTC & &
\end{tabular}




\begin{tabular}{|c|c|c|c|}
\hline 16 & JT & Join Together: Group Theory \& Group Skills & B \\
\hline 17 & IB & Intergroup Cognition \& Intergroup Behavior & $\mathrm{B}$ \\
\hline 18 & DM & Group Decision Making & $\mathrm{B}$ \\
\hline 19 & AGP & Socio-Psychological Aspect of Group Process & $\mathrm{J}$ \\
\hline 20 & GC & Group Dynamics & $\mathrm{B}$ \\
\hline 21 & LP & Group Work: Learning and Practice & $\mathrm{B}$ \\
\hline 22 & LTS & Learning Through Small Group Discussion: A Study of Seminar Work in Higher Education & $\mathrm{B}$ \\
\hline 23 & DWB & Group Process: Dynamics Within and Between Groups & $\mathrm{B}$ \\
\hline 24 & SGW & Successful Group Work & $\mathrm{B}$ \\
\hline 25 & CMC & Cooperation in the Multi-Ethnic Classroom & $\mathrm{B}$ \\
\hline 26 & GPE & Group Performance & $\mathrm{B}$ \\
\hline 27 & CST & Communication in the Small Group: Theory and Practice & $\mathrm{B}$ \\
\hline 28 & GPC & Group Process in the Classroom & $\mathrm{B}$ \\
\hline 29 & GET & Groupwork in Education and Training: Ideas in Practice & $\mathrm{B}$ \\
\hline 30 & GDR & Group Dynamics: Research and Theory & $\mathrm{B}$ \\
\hline 31 & ISG & Interaction in Small Groups & $\mathrm{B}$ \\
\hline 32 & HSG & Handbook of Small Group Research & $\mathrm{B}$ \\
\hline 33 & LTG & Learning Through Group Experience & $\mathrm{B}$ \\
\hline 34 & TGT & T-Group Theory and Laboratory Method: Innovation in Re-education & $\mathrm{B}$ \\
\hline 35 & MTM & Modern Theory and Method in Group Training & $\mathrm{B}$ \\
\hline 36 & STD & The Structure and Dynamics of Organizations and Groups & $\mathrm{B}$ \\
\hline
\end{tabular}

In the Table I, we list the sequence number, the name, the title, and the types of samples. From the sequence number, we can know that the total number of the samples in this study is 36. In 'The Name of Samples' column, we define the different names for the samples. 'The title of literature' is the title of each book or academic published papers in journals. There are two types' samples in our content analysis, which are listed in the column of 'The types of samples'. 'B' means book and ' $\mathrm{J}$ ' means journal. From table I, we can know there is only one sample was chosen from the journal.

We organize these samples into different categories in terms of their main characteristic. The categories and the distribution number are listed in Table II.

TABLE II.

CATEGORIES OF THE SAMPLES

\begin{tabular}{|c|c|c|c|c|}
\hline No. & Categories & The Name of the Samples & $\begin{array}{l}\text { Distribution } \\
\text { Number }\end{array}$ & Percentage (\%) \\
\hline 1 & Group Communication & CL, WG, CST, & 3 & 8.33 \\
\hline 2 & Group Performance & GPE & 1 & 2.78 \\
\hline 3 & Group Interaction & IC, ISG & 2 & 5.56 \\
\hline 4 & Group Process & GP, AGP, DWB, GPC & 4 & 11.11 \\
\hline 5 & Group Learning & LG, SG, LE & 3 & 8.33 \\
\hline 6 & Group Dynamics & DG, GD, GC, GDR, STD & 5 & 13.89 \\
\hline 7 & Group Work & GT, GA, GR, GK, LP, SGW, CMC, GET & 8 & 22.22 \\
\hline 8 & T-Group & TGT, MTM & 2 & 5.56 \\
\hline 9 & Group Experience & LTG & 1 & 2.78 \\
\hline 10 & Group Motives & MG & 1 & 2.78 \\
\hline 11 & Group Tutoring & GTC & 1 & 2.78 \\
\hline 12 & Group Skills & $\mathrm{JT}$ & 1 & 2.78 \\
\hline 13 & Inter-group Behaviour & IB & 1 & 2.78 \\
\hline 14 & Group Decision Making & DM & 1 & 2.78 \\
\hline 15 & Group Discussion & LTS & 1 & 2.78 \\
\hline 16 & Others & HSG & 1 & 2.78 \\
\hline
\end{tabular}

The samples can be categorized into 16 issues according to their main topic, which are listed in the column of 'the name of the samples' in Table II. From 'distributed number', we know how many samples are included in each category. 'Percentage' gives us the further information about the ratio of each category in the total samples. The maximum category of sample is 'group work' (22.22\%). 'Group dynamic' (13.89\%) is the second maximum category. 'Group process' (11.11\%) is the third maximum. 'Group communication' (8.33\%) and 'group learning' (8.33\%) are the fourth maximum. 'Group interaction' (5.56\%) and 'T-group' (5.56\%) are the fifth maximum. Others (2.78\%), which include 'group performance', 'group experience', 'group motives', 'group tutoring', 'group skills', 'inter-group behavior', 'group decision making', 'group discussion', and 'others' are the sixth.

The publishing dates of these samples were presented in Table III. The time span was from 1962 to 2000 (38 years), which represented a long term perspective on group learning. Field research was most active in 1978, 1984, and 1994. Four samples had been published respectively in each of these three years (11.11\%).

The 1970's was the most active decade with twelve samples were published, followed by the 1990's with nine samples. The 1960's and 1980's were quite similar to six or seven books each. 


\begin{tabular}{|c|c|c|c|c|}
\hline Year & Samples & $\begin{array}{l}\text { Decade } \\
\text { Dist. } \\
\text { Number }\end{array}$ & $\begin{array}{l}\text { Dist. } \\
\text { Number }\end{array}$ & $\begin{array}{c}\text { Percentage } \\
(\%)\end{array}$ \\
\hline 1962 & HSG & \multirow{5}{*}{6} & 1 & 2.78 \\
\hline 1963 & STD & & 1 & 2.78 \\
\hline 1964 & DG, TGT & & 2 & 5.56 \\
\hline 1966 & LTG & & 1 & 2.78 \\
\hline 1968 & GDR & & 1 & 2.78 \\
\hline 1971 & MG & \multirow{7}{*}{12} & 1 & 2.78 \\
\hline 1972 & MTM & & 1 & 2.78 \\
\hline 1974 & GD & & 1 & 2.78 \\
\hline 1975 & ISG & & 1 & 2.78 \\
\hline 1976 & GK & & 1 & 2.78 \\
\hline 1978 & $\begin{array}{l}\text { LTS, GPC, } \\
\text { LP, GP }\end{array}$ & & 4 & 11.11 \\
\hline 1979 & $\begin{array}{c}\text { GTC, LE, } \\
\text { GR }\end{array}$ & & 3 & 8.33 \\
\hline 1981 & GA & \multirow{3}{*}{7} & 1 & 2.78 \\
\hline 1984 & $\begin{array}{l}\text { DM, GT, } \\
\text { LG, CL }\end{array}$ & & 4 & 11.11 \\
\hline 1989 & CST, SG, & & 2 & 5.56 \\
\hline 1990 & GC & \multirow{5}{*}{9} & 1 & 2.78 \\
\hline 1994 & $\begin{array}{l}\text { CMC, GET, } \\
\text { GPE, JT }\end{array}$ & & 4 & 11.11 \\
\hline 1995 & AGP, IC & & 2 & 5.56 \\
\hline 1996 & SGW & & 1 & 2.78 \\
\hline 1998 & IB & & 1 & 2.78 \\
\hline 2000 & DWB, WG & 2 & 2 & 5.56 \\
\hline
\end{tabular}

The primary coding system is developed according to the relevant research on the influencing factors of group learning. The fundamental factors are involved in this primary coding system. The coding system includes three main contents, i.e., code, definition, and example. This primary coding system is an open-ended system which means the extra influencing factors can be added to the coding system when is identified from the literature. The developing process of coding system includes three steps, i.e., developing the primary coding system, new influencing factor is added into the primary coding system, and developing a relative coding system (see Figure 3).

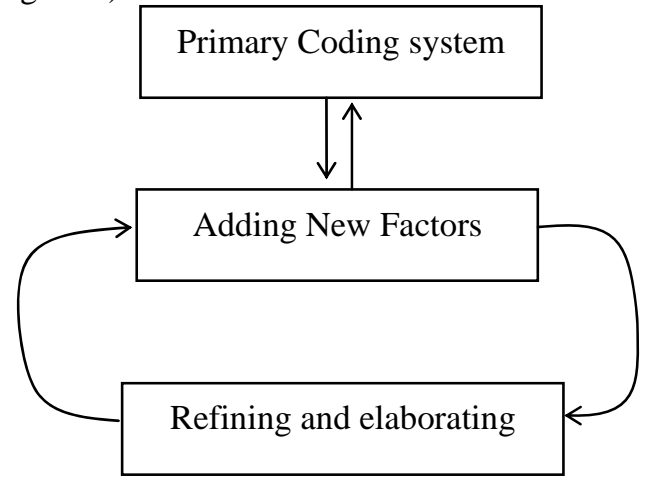

Figure 3. The process to construct the norms of coding system

\section{Step 1: Constructing the primary coding system}

The primary coding system is built to analyze a common group learning process, which is the foundation to build a coding system. Certainly, there are some influencing factors which are connected with group learning process, which are easily gathered through simply analysis. We deal with this work in terms of a framework described by Hackman and Morris [12]. They considering that there are three classes of variables, e.g., effort, performance strategies, and knowledge and skill, are the most powerful proximal causes of group task effectiveness. These variables can be expressed in an 'input-process-output' sequence for different types of tasks (see Figure 2).

The primary coding system can be built according to an analysis this framework, which includes some influencing factors to the group performance effectiveness, such as 'group composition', 'group norms', 'group task', 'group interaction', 'group strategies', 'group performance', 'group effectiveness', 'group outcomes', and 'group design'. However, the ideal coding system cannot be acquired according to this way. The primary coding system need following remedy.

\section{Step 2: Adding new factors into the primary coding} system

We define our coding system as a self-expanding and self-maturing system, which means that it can be mended according to the addition of new factors into the primary coding system. These factors can be analyzed and collected from the specific samples (books and journals). It means that this coding system is opened and not a ready-made coding system can be used into this work. Therefore, this process also can be considered as the way to build a coding system for content analysis.

\section{Step 3: Refining and elaborating the coding system}

The primary coding system can be refined and elaborated after continual remediation. The relatively complete coding system will be built during our content analysis. Definitely, if we want to improve the precision of the coding system, further remediation also is needed.

\section{DATA COLLECTION}

The data in this research was gathered from the samples through content analysis in terms of the coding system. In order to collect data, we designed a form and named it "Data Collection Form via Content Analysis," which was devised in terms of the coding system. Each books or paper uses one form for its data collection. The new influencing factors are added in this form and also are added into the coding system.

Generally, data collection in content analysis should be guided by a coding system. Moreover, participants need to be trained first in order to in-depth fully comprehend the coding system. In this study, because there is no predefined coding system, we do not need to collect data according to the general way. Our work in data collection includes three steps.

\section{Step 1: Quoting the relevant sentences or paragraphs from the literature}

Reading the books and journals (the chosen samples) in order to quote the paragraphs when it expresses the meaning which is connected to the effectiveness of group learning process. When they are identified, they are then quoted. The original materials from quotation work includes the index number $\left(\mathrm{CA} 00^{* *}, \mathrm{CAB}^{* *}, \mathrm{CAC}^{* *}\right.$, and $\left.\mathrm{CAD}^{* *}\right)$, quoted content, page number, and 
influencing factors. This work can be done partly depend on the primary coding system. The paragraph will be quoted when it meet the norm of coding. For instance:

CAB008: We suggest that the key to understanding the 'group effectiveness problem' is to be found in the on-going interaction process which takes place among group members while they are working on a task. P2 --- [19]

CAC028: As the end of the period of observation it is possible to collate the observations in each category and provide an interaction profile of the group as a whole (in terms of the percentages of time spent engaged on the different categories of behavior), of individuals in the group, or (the most complete picture of all) the proportion of time each person spent interacting with the others and in what manner. P42 --- [20]

When the quotation work is finished, these original quoted materials can be used to analyze the relevant influencing factors according to the coding system.

Step 2: Analyzing the sentences or paragraphs and to identify or extract the influencing factors of group learning

Tick in the data collection form in terms of the quoted paragraph from the samples. When the quotation work is finished, the original quoted materials can be used to tick mention highlight factors in the data collection form. The frequency of factors does not need to be calculated in the same book or journal. Therefore, the mentioned factors in one book or journal only are recorded one times. Some examples demonstrate how we recognize the influencing factors for this purpose, for examples

CA0006: A supplement to Smith's paper is my own chapter summarizing some group behavior theories for community workers. P14 ------ (Group behavior) [21]

The author introduces how he summarizes group behavior theories in his own chapter. I recognize it is related to group behavior. Therefore, I quote it out and categories it as group behavior.

CAB029: In summary, these studies suggest that the impact of group interaction on group performance can be analyzed systematically and that the results of such analyses can increase understanding of the reasons why some groups are more effective than others. P8 -- (group interaction, group performance) [19]

This paragraph introduces the results of authors' studies. From this paragraph, I can extract group interaction and group performance.

CA0032: Group life explored in this way may be a liberating experience but often proves to be a dislocating one for individuals when they have to relate to people who have not been expose to the same liberating experience, and have to discover in that context how to be more authentically themselves and transform habitual role behaviors. P31 ---- (Group life, group experience, group setting, role behaviors) [21]

From this paragraph, I can identify some influencing factors of group learning, i.e., group life, group experience, group context, and role behaviors.

CA0114: It has been found that groups comprising between ten and thirteen participants, including one consultant, provide optimum conditions for learning about group processes in a simple social setting. P87 --- (group composition, group size, group context, group processes, group community, and role playing) [21]

Researcher introduces group composition which includes group size, role playing, and group context in a simple social setting (community). From this paragraph, I can extract few influencing factors of group learning, i.e., group composition, group size, group context, group processes, role playing, and group community.

CA0211: Developing the self-confidence of members in their ability to fact authority figures and to take some control of their own environment can be helped in the group through the planning of occasions where the group negotiates about rules or resource or invites visitors with resources into meetings. P186 - 187 ---(Individual ability, Group environment, Group Negotiation, group rules, Group Resources, group meeting) [21]

This paragraph introduces how to develop the selfconfidence of members. The influencing factors of group learning can be identified as individual ability, group environment, group negotiation, group rules, group resources, and group meeting.

CAB030: One hundred and eight experimental groups spent 15 minutes on each of four 'intellective' tasks. Four hundred and thirty-two separate transcripts of group interaction and 432 group products were obtained. A total of 144 different group tasks were used in the research, 48 each of three task 'types': (1) 'production' tasks, which require the production and presentation of ideas or images; (b) 'discussion' tasks, which require and evaluation of issues; and (c) 'problem-solving' tasks, which require specification of a course of action to be followed to resolve some problem. P9 ---- (group interaction, group tasks, group discussion, group problem-solving, group evaluation) [19]

This is a long paragraph. The author summarizes the findings of their study on group learning. Lots of influencing factors of group learning can be found out from it, i.e., group task, group interaction, group 
production, group discussion, group problem- solving, and group evaluation.

CAB194: At the end of this first set of group trials, group performance was scored and points based on the group leader. P127 --- (group performance, group leader) [19]

From this sentence I can identify two influencing factors of group learning, i.e., group performance and group leader.

When the influencing factors are identified, write them down on the each sentence or paragraph. Then, tick in the data collection form in terms of the results of the identification. I do not analyze the frequency and percentage of influencing factors in the same book or journal. Therefore, a certain influencing factor is found in one book or journal paper, it was just ticked one time.
Step 3: Adding new influencing factors into the data collection form

When a 'ticked' work meets the situation where the factor cannot be found in the data collection form, in this case, the factor will be added into the data collection form. The blank cells in the form can be used for this purpose. Meanwhile, the new factor also needs to be added in the coding system, and furthermore, it can be considered as the rule which will be used to deal with the other samples.

\section{DATA ANALYSIS}

In order to approach the further analysis, the data collected through content analysis should be given a brief introduction first. We use SPSS as a processing tool to get the data summary. The frequency of each factor can be described in Figure 4.

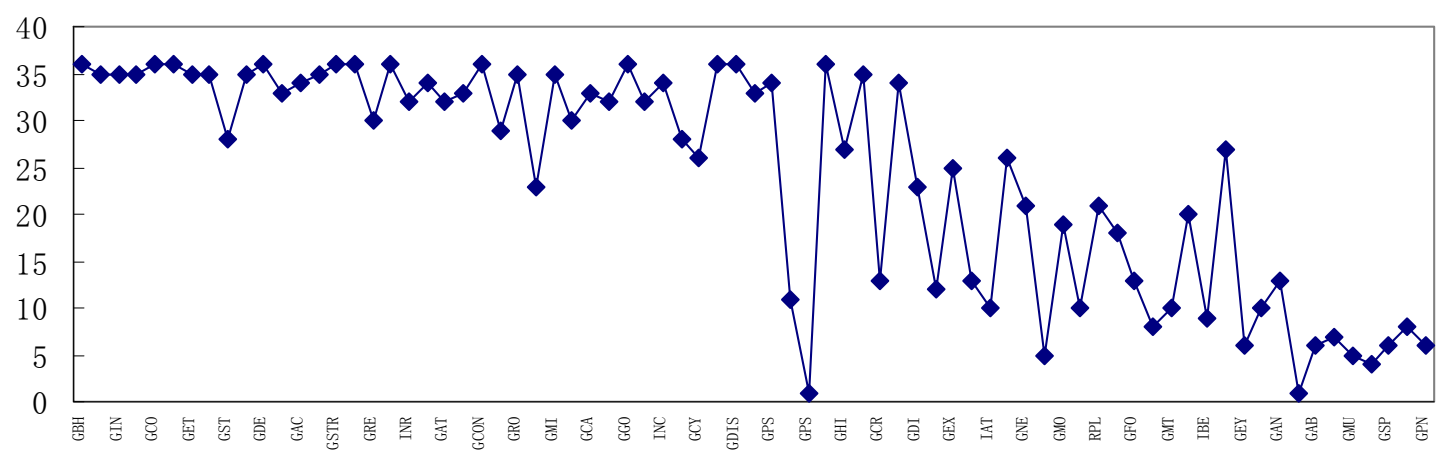

Figure 4. The frequency of influencing factors

In Figure 4, the range of frequency is 35.13 factors are less than 10, which are 'group duration' (GDU, 5), ‘individual goal’ (IGO, 8), ‘individual decision’ (IDE, 1), 'individual behaviour' (IBE, 9), 'group efficiency’ (GEY, 6), 'individual performance' (IPE, 1), 'group ability' (GAB, 6), 'group consciousness' (GCS, 7), 'group movement' (GMV, 5), 'group controversy' (GCT, 4), 'group progress' (GSP, 6), 'group think' (GTH, 8), and 'group presentation' (GPN, 6). 12 factors are equal to 36, which mean they got full recognized. These factors are GBH (group behaviour), GCO (group communication), GTA (group tasks), GDE (group decision), GSTR (group structure), GSI (group size), GEN (group environment), GCON (group conflict), GGO (group goals), GRES (group resources), GDIS (group discussion), and GLE (group leader). 12 factors are more than 10 (included) and less than 20. 13 factors located 20 (included) and 30. Other 25 factors are more than 30 (included) and less than 36.

The number of frequencies is less than 10 does not mean it cannot be used and less validity. It just means that it was referred not too much in these chosen samples. The number is bigger, which means it got more concern by field researchers. In this study, we also need pay more concern and well-analysis for these factors.

\section{RESULTS AND CONCLUSION}

We can get the influencing factors of group learning process from the analysis on literature, and present them in Table IV. There are 62 influencing factors in total.

TABLE IV.

THE INFLUENCING FACTORS OF GROUP LEARNING PROCESS

\begin{tabular}{lcccc}
\hline No. & Name & Freq. & No. & Name \\
\hline 1 & GFE (Group feedback) & 33 & 32 & Freq. \\
2 & GBH (Group behaviour) & 36 & 33 & INR (Interpersonal relationships) \\
3 & GCO (Group communication) & 36 & 34 & GAT (Group attitudes) \\
4 & GDE (Group decision) & 36 & 35 & GSK (Group skills) \\
5 & GSTR (Group structure) & 36 & 36 & GDY (Group dynamics) \\
6 & GSI (Group size) & 36 & 37 & GRE (Group rewards) \\
7 & GEN (Group environment) & 36 & 38 & GME (Group methods) \\
8 & GCON (Group conflict) & 36 & 39 & RIN (Relationship of inter-group) \\
9 & GGO (Group goals) & 36 & 40 & GST (Group strategies)
\end{tabular}




\begin{tabular}{lcll}
10 & GRES (Group resources) & 36 & 41 \\
11 & GDIS (Group discussion) & 36 & 42 \\
12 & GTA (Group tasks) & 36 & 43 \\
13 & GLE (Group leader) & 36 & 44 \\
14 & GPE (Group performance) & 35 & 45 \\
15 & GIN (Group interaction) & 35 & 46 \\
16 & PID (Personal identity) & 35 & 47 \\
17 & GEF (Group effectiveness) & 35 & 48 \\
18 & GPR (Group process) & 35 & 49 \\
19 & GAS (Group assessment) & 35 & 50 \\
20 & GCOH (Group cohesion) & 35 & 51 \\
21 & GRO (Group role) & 35 & 52 \\
22 & GMI (Group maintenance) & 35 & 53 \\
23 & GNO (Group norms) & 35 & 54 \\
24 & GAC (Group activities) & 34 & 55 \\
25 & GMA (Group management) & 34 & 56 \\
26 & INC (Individual contribution) & 34 & 57 \\
27 & GPS (Group Problem solving) & 34 & 58 \\
28 & GCOM (Group composition) & 34 & 59 \\
29 & GOU (Group outcomes) & 33 & 60 \\
30 & GWO (Group work) & 33 & 61 \\
31 & GCA (Group categories) & 33 & 62 \\
\hline
\end{tabular}

In order to analyze these factors in depth, we categories them into four groups, including Planning, Organizing, Learning process, and Evaluation. According to these categories, 53.23\% influencing factors are related to learning process. Comparing with Hackman and Morris's framework (Figure 1 and 2), a diagram was designed to present a group learning process based on integrating influencing factors together with the four components, including planning, organizing, learning process, and evaluation (see Figure 5).

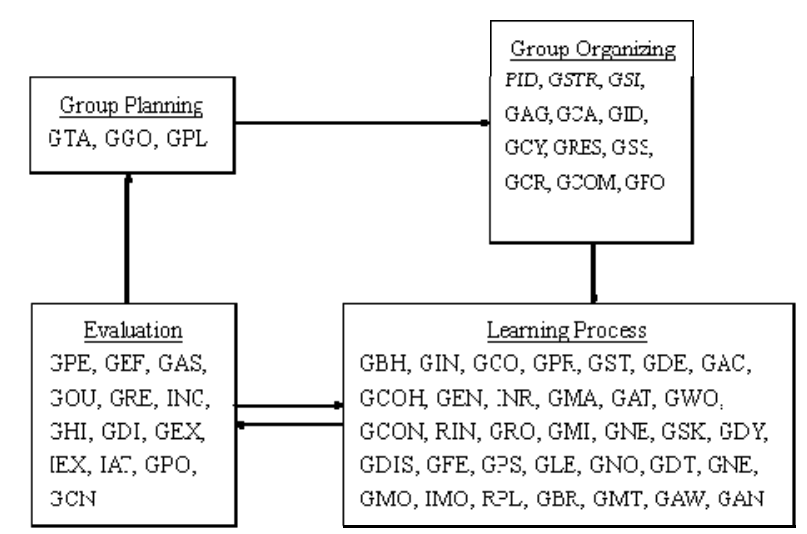

Figure 5. A group learning process

Group planning is the first step in the group learning process. The group learning organizer needs to be clear about the group learning task, the objectives, and the other related issues. In the group organizing step, the organizer will choose or define a group structure, the optimal group size, a draft agenda, heterogeneous group, and optional group names. Furthermore, group resources also need to be prepared in this stage. Traditionally, group learning can be considered as a learning community. Some elements related to a community can used to organize group, e.g., creativity, norms, belief, and status.

The learning process is the essential component when we organize group learning, which mainly determine the performance of group learning. Some factors must be well considered, such as interaction, communication, negotiation, skills, strategies, feedback, leader, role play, brainstorming, and motivation. Interpersonal and intergroup relationship also should be balanced carefully.

Evaluation is the last stage in the cycle of our suggested group learning process. Some factors need to be considered, such as performance, effectiveness, outcomes, contributions, history, experiences, and productivity. The purpose of evaluation is to assess group work and to know whether the group learning is successful or not. In this stage, group diagnosis will be used to examine the outcomes and "effectiveness" of group learning. The results can be used to evaluate the group learning process. Meanwhile, these results are adopted to adjust the group planning in order to commence a new group learning process.

\section{SUMMARIES}

This paper explores the influencing factors of the group learning process through content analysis. 36 typical books and journals were chosen as samples. We calculated the frequencies of the influencing factors according to whether they were displayed in the samples or not. 75 factors were analyzed and 62 influencing factors have been identified. The frequency expresses the different concerns by different researchers and it does not mean a factor with small frequency is not important. It also indicates that their 'weighing' is different. The influencing factors can be used for organizing or analyzing a group learning process, and for designing a questionnaire to have an in-dept analysis. A diagram of a group learning process was discussed in this paper as well. It is a cyclic system which can be used for explaining how to use these influencing factors to guide group learning.

\section{ACKNOWLEDGMENTS}

This paper was supported by National Educational Project for "Eleven-Five” Planning (No. DCA080147) and Guangdong Social-Science funds for Educational 
Research Project (No. 07SJZ003), and SRF for ROCS, SEM.

\section{REFERENCES}

[1] Honassen, D., \& Kwan, H. I. "Communication Patterns in Computer Mediated versus Face-to-Face Group Problem Solving”. Educational Technology, Research and Development, 2001, 49 (1), pp 35.

[2] Duisburg, M., \& Hoope, U. "Computer supported interaction analysis of group problem solving". In the Proceedings of the Conference on Computer Supported Collaborative Learning, CSCL-9, pp: 398-405. Palo Alto, CA, December 1999.

[3] Brabdon, D. P., \& Hollingshead, A. B. "Collaborative Learning and Computer-Supported Groups". Communication Education, 1999, 48 ( 2), pp: 108-125.

[4] Klein, J. D., \& Doran, M. S. "Implementing Individual and Small Group Learning Structures with a Computer Simulation”. Educational Technology, Research and Development. 1999, 47 (1), pp: 47.

[5] Ross, J. A., \& Cousins, J. B. "Brief research report: Intentions to seek and give help, and behaviour in cooperative learning group". Contemporary Educational Psychology, 1994, 19, pp: 476-482.

[6] Brush, T. A. "The effects of group composition on achievement and time on task for students completing ILS activities in cooperative pairs". Journal of Research on Computing in Education, 1997, 30 (1), pp: 2.

[7] Collins, B. "WWW-based environments for collaborative group work". Education and Information Technology, 1998, 3, pp: 231-245.

[8] Stenmark, D. "Group cohesiveness and extrinsic motivation in virtual groups: lessons from an action case study of electronic brainstorming”. In the Proceedings of the 35th Hawaii International Conference on System Sciences. 2002.

[9] Jaques, D. "Learning in Groups". London: Croom Helm Ltd., 1984.

[10] Reynolds, M. "Groupwork in Education and Training, Ideas in Practice”. London: Kogan Page Ltd, 1994.

[11] McGrath, J. E. Social Psychology: A Brief Introduction. New York: Holt, 1964.

[12] Hackman, J. R., \& Morris, C. G. (1978). Group tasks, group interaction process, and group performance effectiveness: a review and proposed integration. In L. Berkowitz (Ed.), Group Processes: Papers from Advanced in Experimental social Psychology. London: Academic Press.

[13] Lally, V., \& Latt, M. De. "A quartet in e, investigating collaborative learning and tutoring as knowledge creation processes". In B. Wasson, S. Ludvigsen, and U. Hope (ed.), Designing for Change in Networked Learning Environments, Proceedings of the International Conference on Computer Support for Collaborative Learning 2003. Dordrecht: Kluwer Academic Publishers.

[14] Barnes, D., \& Todd, F. "Communication and Learning in Small Group”. London: Routledge \& Kegan Paul Plc., 1984.
[15] Henri, F. “Computer conferencing and content analysis”. In A. R. Kaye, (ed.), Collaborative Learning Through Computer Conferencing, The Najaden Papers. London: Springer-Verlag, 1992.

[16] Krippendorff, K. "Content Analysis: An Instruction to Its Methodology”. London: Sage Publications, 1980.

[17] McKernan, J. Curriculum Action Research. London: Kogan Page, 1991.

[18] Berg, B. L. (1998). Qualitative Research Methods for the Social Sciences (3rd Ed.). London: Allyn and Bacon, 1998

[19] Berkowitz, L. (1978). Group Process: Papers from Advances in Experimental Social Psychology. New York: Academic Press, 1978.

[20] Brown, R. (2000). Group Process: Dynamics Within and Between Groups (2nd Ed.). Oxford: UK, 2000.

[21] McCAughan, N. (1987). Group Work: Learning and Practice. London: George Allen \& Unwin, 1987.

Jianhua Zhao was graduated from School of Educational Studies, the University of Sheffield, United Kingdom and successful gained $\mathrm{PhD}$ in the field of Education in 2006. He also acquired the first $\mathrm{PhD}$ from School of Information Technology in Education, the University of South China Normal, China in 2002.

He is a Professor at the School of Information Technology in Education, the University of South China Normal from 2007. He was a research associate at the Centre for Studies of Advanced Learning Technology, Department of Education, Lancaster University, United Kingdom from 2005 2007. He was also a PhD Fellow at Institute of Advanced Studies, United Nations University from 2000 2001, Tokyo, Japan. He has published more than 100 journal papers and 6 books in the field of e-learning, educational technology, computers in education, intelligent tutoring system, instructional design, and teacher education (professional development. Current, he is a leader for eight national and international research projects.

Prof. Zhao is a director of the Institute of Learning Sciences and Technologies (ILST), an execute committee member of Global Chinese Society for Computers in Education (GCSCE).

Yinjian Jiang was graduated from School of Foreign Languages Studies, the University of Xiangtan Normal in 1993. She was graduated from School of Foreign Languages, Hunan Normal University and gained MA degree in 1999.

She is an Associate Professor at the School of Foreign Languages, Guangdong Polytechnic Normal University from currently. She has been working at Zhongnan University of Technology in Changshan from 1993 2000. She has published 20 journal papers in the field of language learning and teaching, computer assisted language learning, and applied linguistics. Currently, she is conducting three research projects and has carried out interesting research findings.

Miss Jiang is a director of the Centre for Studies of Advanced English. 